\title{
АЛГОРИТМ ОЦЕНКИ ДЕЙСТВИЙ ПАРАШЮТИСТА В АВТОМАТИЗИРОВАННОМ РЕЖИМЕ ДЛЯ УПРАВЛЕНИЯ УРОВНЕМ ОСВОЕНИЯ НА ДИНАМИЧЕСКОМ ТРЕНАЖЕРЕ
}

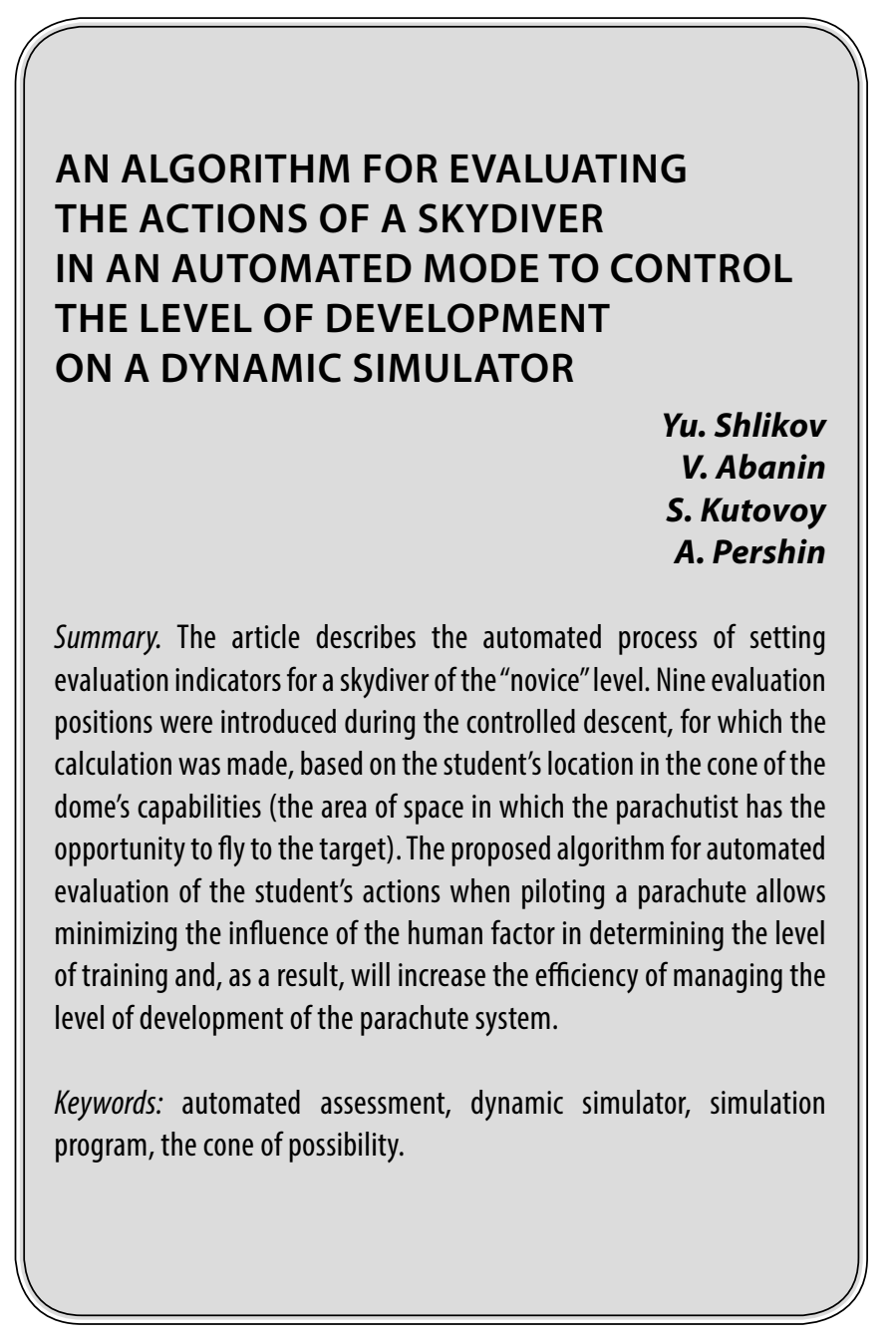

\section{Введение}

$\mathbf{0}$ дной из важнейших задач в процессе подготовки специалиста к пилотированию парашюта типа «крыло» является его обучение правильным действиям в момент захода в район, с которого начинается построение захода на цель (исходный район), и отработки действий при приземлении [1, 2]. Рассматриваемый участок траектории полёта является наиболее опасным, с точки зрения травматизма, так как данный тип парашютов обладает высокой горизонтальной скоростью, а неправильные действия парашютиста, могут привести к нарушению требований безопасности, или вообще к летальному исходу прыжка.
Шлыков Юрий Николаевич

Адъюнкт, Рязанское гвардейское высшее воздушно-десантное командное училище

shlykov76@mail.ru

Абанин Владислав Сергеевич

К.т.н., профессор, Рязанское гвардейское высшее воздушно-десантное командное училище

vlad-ac@mail.ru

Кутовой Сергей Сmenaнович

Д.т.н., профессор, Рязанское гвардейское высшее воздушно-десантное командное училище

kutovoyss@mail.ru

Периин Андрей Сергеевич

Старший преподаватель, Рязанское гвардейское высшее воздушно-десантное командное училище

Sima-per@rambler.ru

Аннотация. В статье описан автоматизированный процесс выставления оценочных показателей для парашютиста уровня «новичок». Введены девять позиций оценивания в ходе управляемого снижения для которых произведен расчет, по нахождению обучающегося в конусе возможностей купола (область пространства, находясь в которой парашютист имеет в03можность долететь до цели). Предложенный алгоритм автоматизированной оценки действий обучающегося при пилотировании парашюта позволяет минимизировать влияние человеческого фактора при определении уровня подготовки и, как следствие, повысит эффективность управления уровнем освоения парашютной системой (ПС).

Ключевые слова: автоматизированная оценка, динамический тренажер, программа имитационного моделирования, конус возможностей.

Сделать процесс обучения более безопасным возможно с использованием учебных средств (тренажеров), позволяющих получить базовые навыки пилотирования парашютов типа «крыло» на земле, а за счет внедрения автоматизации системы повысить эффективность обучения.

При отработке действий парашютиста должны учитываться их правильность, полнота и своевременность, а по итогам выполненного упражнения производиться оценивание [3]. Недостатком оценки, производимой инструктором, является присутствие человеческого фактора, в результате чего возрастает вероятность ошибки инструктора при оценке обучающегося, и как 


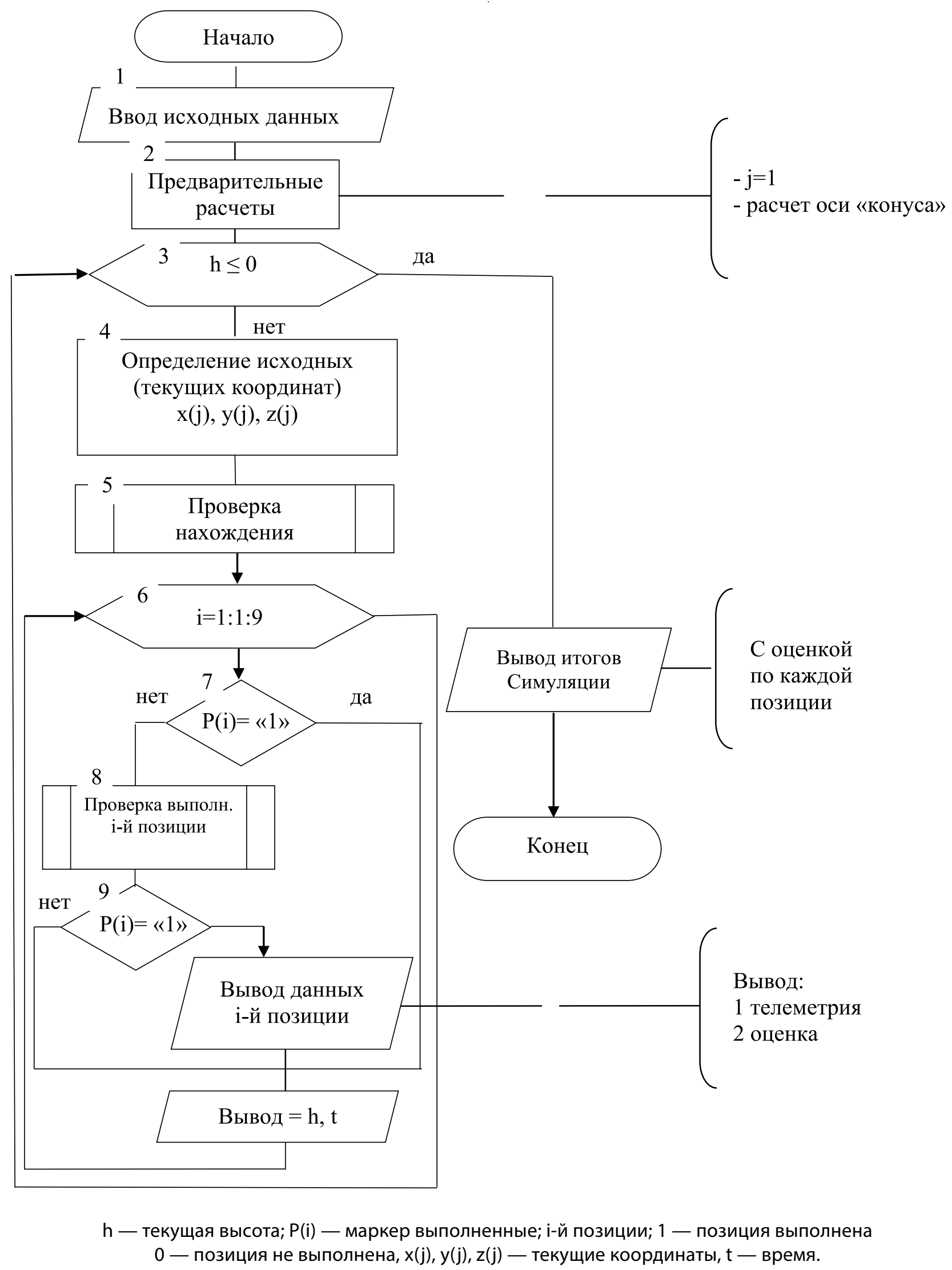

Рис. 1. Алгоритмы действий парашютиста при пилотировании на парашютной системе специального назначения с высоты 400 м 


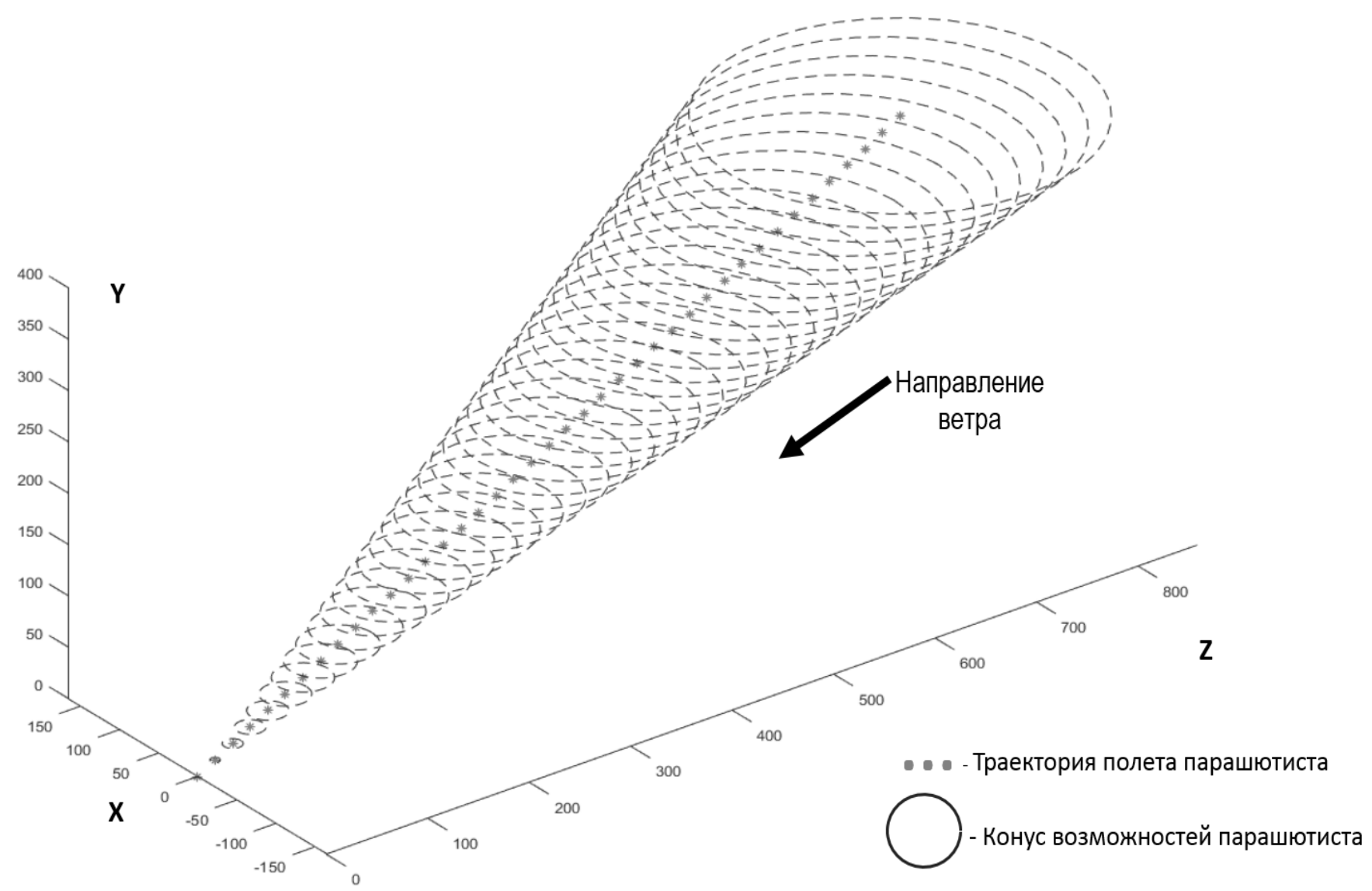

OY — высота над площадкой приземления; OZ — ось удаления от точки приземления

Рис. 2. Графическое представление конуса возможностей оси X, Y, Z

следствие, не эффективное использование времени тренировки.

\section{А^горитм оченки Аействий парашютиста в автоматизированном режиме $\Delta \wedge$ я управления уровнем освоения на $и$ иамическом тренажере}

Одна их целей алгоритмизации оценки действий парашютиста при пилотировании на парашюте типа «крыло» заключается в снижении загруженности инструктора как контролирующего процесс обучения специалиста. Принимая во внимание аэродинамику планирующего парашюта, несущие способности купола, загруженность купола, следует учитывать диапазоны основных показателей при описании алгоритма оценки. На этапе любого синтеза сложной системы обычно вводятся определенные ограничения. Принимаются следующие допущения:

- полётная масса планирующей парашютной системы (ППС) равна 90 кг;

- вертикальная скорость снижения на ППС постоянна и равна 5 м/с;
- горизонтальная скорость ППС не превышает $10,5 \mathrm{~m} / \mathrm{c}$.

Разрабатываемый алгоритм описывает порядок оценки действия парашютиста на участке траектории с высотами от 400 метров до момента приземления. При этом предлагается проводить контроль выполнения девяти позиций в критически важных точках траектории полёта. Алгоритм автоматизированной оценки действий парашютиста является открытым, то есть при необходимости возможно изменение интервала высот и добавление новых позиций для контроля без существенной его доработки.

Основной цикла алгоритма оценки, включающий в себя переменные, является высота $h(j)$ и рассчитывается за каждый проход, где $j-$ номер прохода цикла. В процессе каждого прохода происходит измерение и коррекция телеметрических данных парашютиста, в интересах точной оценки его действий (рисунок 1).

Программная реализация алгоритма автоматизированной оценки должна включать ведение лога для дан- 


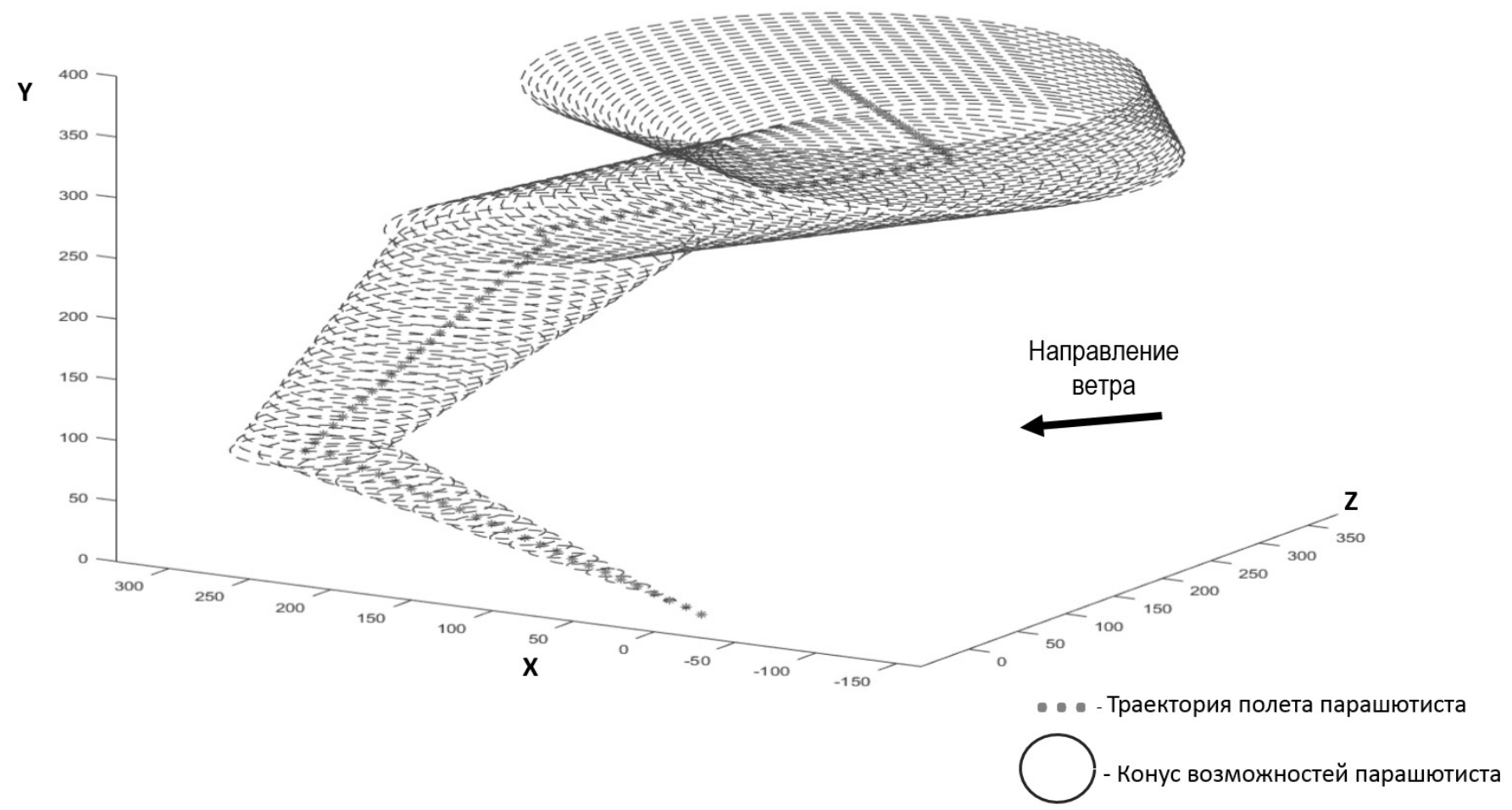

Рис. 3. Графическое представление конуса возможностей сложной формы

ного прыжка, для того, чтобы иметь возможность разбора ошибок по окончанию упражнения на тренажёре.

Основной цикл завершается, когда высота равняется нулю. Перед началом основного цикла вводятся исходные данные (рисунок 1 блок 1), необходимые для расчета правильной траектории прыжка (конуса возможностей).

Параметры конуса возможностей зависят от направления и силы ветра, качества парашюта рисунок 2.

В интересах расчета конуса возможностей проводится моделирование идеальной траектории парашютиста (рисунок 1 блок 2), которая является осью конуса, причем каждый срез конуса проецируется на ось отдельно. Таким образом, результирующий конус возможностей пространственно разнесен по осям (идеальной траектории) рисунок 2, и может представлять собой геометрическую область достаточно сложной формы рисунок 3, в зависимости от моделируемой траектории.

Красным пунктиром на рисунке 2 обозначена ось конуса возможностей - идеальная траектория движения парашютиста, синим - его граница в каждом срезе высоты. В зависимости от проекции оси конуса возможностей на горизонтальную плоскость он может прини- мать более сложные формы, как например на рисунке 3.

Расчет конуса возможностей происходит на основании математической модели, учитывающей горизонтальную и вертикальную скорость, с учётом полётной массы и технических параметров ППС.

Реализованный алгоритм в программе для ПЭВМ на языке MATLAB предполагает построение трёхмерной траектории (в упрощенном варианте - траектория двухмерная при этом значение оси $\boldsymbol{Y}$ фиксировано).

Первым шагом выполнения основного цикла алгоритма автоматизированной оценки действий парашютиста (рисунок - 1 блок 3), является определение текущих координат ПС $x(j), y(j), z(j)$ в декартовой системе координат с началом отсчёта в точке входа в исходный район на высоте 400 метров (рисунок - 1 блок 4). Программно-аппаратный комплекс тренажера определяет текущие координаты движения парашюта с учётом воздействия парашютиста на органы управления [4]. При этом происходит документирование траектории и запись данных в файл, чтобы впоследствии, по окончании упражнения возможно было произвести анализ и разбор ошибок [5].

В программе имитационного моделирования выполнению алгоритма предшествует расчет траектории 
парашютиста на высотах от 400 метров до точки приземления $(h(j)=z(j)=0$ метров). При работе алгоритма данные считываются из заранее рассчитанного массива координат текущего положения.

Вторым важным этапом оценивания, является определение нахождения обучаемого в конусе возможностей (рисунок - 1 блок 5):

$$
\sqrt{\left(x(j)-x_{K}(j)\right)^{2}+\left(y(j)-y_{K}(j)\right)^{2}} \leq R_{K}(j) ;
$$

где $x_{K}(j)$ и $y_{K}(j)$ координаты «конуса возможностей» для высоты $h(j)$;

$R_{K}(j)$ - допустимый радиус конуса возможностей для высоты $h(j)$.

Расчёт радиуса конуса возможностей, как функции высоты

$R_{K}(j)=f(h(j))$ осуществляется с учётом дополнительных параметров, в частности скорости ветра. В программе имитационного моделирования радиус конуса возможностей выбран постоянным, однако существует возможность провести его расчет на основе любой функциональной зависимости. Для этого необходимо в соответствующей строке программы, написанной на языке MATLAB, задать функцию. В этом случае мы получим линейно убывающий радиус $R_{K}(j)$ конуса возможностей, изменяющийся от 100 метров на высоте 400 метров, до 1 метра на высоте 0 метров, похожий вариант был рассмотрен в работе [6].

Результатом проверки выхода из конуса возможностей является получения $j$-го значения маркера выхода $R_{K \mathrm{M}}(j)$. Переменные данного массива данных имеют логический тип, то есть если выход произошёл, то $R_{K \mathrm{M}}(j)=1$, в противном случае $R_{K \mathrm{M}}(j)=0$. Данный массив учитывается при определении итоговой оценки за прыжок. В принятой методике оценки считается, что выход за пределы конуса возможностей абсолютно недопустим, так как в этом случае исключается возможность попадания в целевую область приземления. Следующим шагом основного цикла алгоритма оценки действий парашютиста является оценка правильности и своевременности выполнения контрольных позиций (рисунок - 1 блок 6).

Это реализовано путём введения подцикла проверки выполнения позиций, в котором осуществляется запуск подпрограмм проверки позиций и ведется журнал, где записываются точки начал и окончания выполнения контрольных позиций, при этом переменной, по которой осуществляется отсчёт выполнения прыжка является высота $h(j)$. Работа подцикла проверки вы- полнения контрольных позиций организована следующим образом:

1. Проверяется маркер выполнения $i-\breve{u}$ позиции $P(i)$ . Данный маркер является массивом логических переменных. Если значение маркера $P(i)=1$, (рисунок -1 блок 7) это означает, что позиция уже выполнена и цикл переходит к проверке маркера $(i+1)-\check{u}$ позиции. В случае если значение данного маркера равно «0» происходит запуск подпрограммы проверки выполнения $i-\breve{u}$ позиции (рисунок - 1 блок 8). При этом в результате работы подпрограммы вносятся изменения в массив данных, соответствующий оценке $i$ - $\breve{~ п о з и ц и и ~}$

2. По окончанию выполнения подпрограммы проверки выполнения $i$-й позиции снова производиться проверка маркера $P(i)$. Если его значение изменилось с «0» на «1» (рисунок 1 блок 9) это означает, что выполнение позиции было завершено в $j$-м проходе основного цикла, соответствующем высоте $h(j)$. В этом случае осуществляется вывод информации о выполненной позиции на рабочее место оператора (в случае работы алгоритма на тренажёре [7]) или в командную консоль (в случае выполнения алгоритма в рамка программы имитационного моделирования).

По завершению выполнения подцикла проверки выполнения позиций, при необходимости, производится вывод информации (в том числе запись в файл) о $j$-м проходе основного цикла, затем алгоритм переходит к обработке следующего, $(j+1)$-го прохода основного цикла.

В интересах проверки навыков обучаемого на завершающем этапе пилотирования, от момента захода в исходный район, до момента приземления, в предложенном алгоритме автоматизированной оценки, производится проверка 9-ти контрольных позиций. К этим позициям относятся:

1. Пилотирование к исходному району;

2. Уход на траверз - (плоскость в пространстве, проходящая через цель и перпендикулярная створу ветра);

3. Пилотирование к точке траверза;

4. Уход на базовую точку - (расчётная точка в пространстве, находясь в которой лицом против ветра парашютист, не совершая манёвров по направлению (кроме корректирующих), управляя парашютом только по скорости, попадает в цель);

5. Пилотирование к базовому району - (район вокруг цели, в котором находится базовая точка);

6. Кратковременно ожидание после 5-й контрольной позиции; 
Таблица 1. Список числовых параметров подлежащих оцениванию

\begin{tabular}{|c|c|c|c|c|c|c|c|c|c|c|}
\hline \multirow{2}{*}{ Параметр } & \multirow{2}{*}{ Обозначение } & \multicolumn{9}{|c|}{ Позиции } \\
\hline & & 1 & 2 & 3 & 4 & 5 & 6 & 7 & 8 & 9 \\
\hline Высота максимальная & $H_{\text {нач }}$ & + & + & + & + & + & + & + & + & + \\
\hline Высота минимальная & $H_{\text {конеч }}$ & + & + & + & + & + & + & + & + & + \\
\hline $\begin{array}{l}\text { Минимальное удаление от точки } \\
\text { приземления }\end{array}$ & $d_{\text {тпнач }}$ & + & - & - & - & - & - & - & - & - \\
\hline $\begin{array}{l}\text { Максимальное удаление от точки } \\
\text { приземления }\end{array}$ & $d_{\text {тпконеч }}$ & + & - & - & - & - & - & - & - & - \\
\hline $\begin{array}{l}\text { Минимальное удаление от } \\
\text { параллельной линии приземления }\end{array}$ & $d_{\text {плпнач }}$ & - & + & - & - & - & - & - & - & - \\
\hline $\begin{array}{l}\text { Максимальное удаление от } \\
\text { параллельной линии приземления }\end{array}$ & $d_{\text {плпконеч }}$ & - & + & - & - & - & - & - & - & - \\
\hline Угол от оси ветра & $\angle \mathrm{A}_{B}$ & + & - & + & - & + & + & + & - & - \\
\hline $\begin{array}{l}\text { Минимальное удаление от линии } \\
\text { приземления }\end{array}$ & $d_{\text {лпнач }}$ & - & - & + & - & - & - & - & - & - \\
\hline $\begin{array}{l}\text { Максимальное удаление от линии } \\
\text { приземления }\end{array}$ & $d_{\text {лпконеч }}$ & - & - & + & - & - & - & - & - & - \\
\hline $\begin{array}{l}\text { Максимальная горизонтальная } \\
\text { скорость }\end{array}$ & $U_{\text {гормакс }}$ & - & - & - & - & - & + & + & - & - \\
\hline $\begin{array}{l}\text { Минимальная горизонтальная } \\
\text { скорость }\end{array}$ & $U_{\text {гормин }}$ & - & - & - & - & - & + & + & - & - \\
\hline Разность горизонтальной скорости и скорости ветра & $U_{\text {гоp }-} U_{6}$ & - & - & - & - & - & - & - & - & + \\
\hline
\end{tabular}

7. Своевременный перевод звеньев управления в верхний режим;

8. Своевременный и технически правильный перевод звеньев управления в нижний режим;

9. Остановка горизонтальной скорости парашютиста.

При этом каждой контрольной позиции соответствует два массива оценочных данных:

- числовой, содержащий численные значения параметров подлежащих оценке (высота начала и окончания выполнения позиции, угол к скорости ветра, удаление от точки приземления, траверза, района приземления и т.д.);

- логический, содержащий логические значения, показывающие выполнение тех или иных действий (оценка взгляда на высотомер, правильность втягивания стропы, оценка угла отклонения, определение точки сноса и т.д.).

Списки параметров и действий формируется исходя из методики пилотирования парашюта типа «крыло». По возможности, эти списки должны быть максимально краткими и содержать критически важные параметры, невыполнение которых является грубым нарушением требований безопасности, либо способно повлечь тяжкие последствия для парашютиста при осуществлении реального прыжка.

Список числовых параметров, подлежащих оцениванию и их соответствие номерам контрольных позиций сведены в таблицу 1.

Перечисленные параметры оценивания выводятся в командную консоль или на рабочее место инструктора после завершения выполнения каждой контрольной позиции [8]. Оценка производится исходя из специальной таблицы оценок, содержащей минимальные и максимальные допустимые значения параметров, для оценивания, по 4-х бальной системе: «2-неудовлетворительно»,

«3-удовлетворительно», «4-хорошо», «5-отлично». Таблица оценок может быть статической или формироваться динамически, на основе априорной информации о скорости ветра, полётной массе, уровне подготовленности парашютиста и иных данных.

Выполнение действий характеризуют логические переменные, список которых, представлен в таблице 2. 
Таблица 2. Список логических параметров, подлежащих оцениванию

\begin{tabular}{|c|c|}
\hline Позиция & Действия \\
\hline \multirow{4}{*}{1} & Оценка правильности втягивания стропы и поворота головы \\
\hline & Оценка отклонения угла \\
\hline & Оценка взгляда на высотомер \\
\hline & Определение точки сноса \\
\hline \multirow{2}{*}{2} & Оценка правильности втягивания стропы и поворота головы \\
\hline & Перемещение звеньев управления \\
\hline \multirow{4}{*}{3} & Оценка правильности втягивания стропы и поворота головы \\
\hline & Оценка отклонения угла \\
\hline & Оценка взгляда на высотомер \\
\hline & Определение точки сноса \\
\hline \multirow{2}{*}{4} & Оценка правильности втягивания стропы и поворота головы \\
\hline & Перемещение звеньев управления в среднее положение \\
\hline \multirow{3}{*}{5} & Оценка правильности втягивания стропы и поворота головы \\
\hline & Оценка отклонения угла \\
\hline & Оценка взгляда на высотомер \\
\hline 6 & Оценка ожидания времени пред переводом звеньев управления \\
\hline 7 & Перевод звеньев управления в верхний режим \\
\hline 8 & Перевод звеньев управления в нижний режим \\
\hline 9 & Остановка горизонтальной скорости ветра и парашюта \\
\hline
\end{tabular}
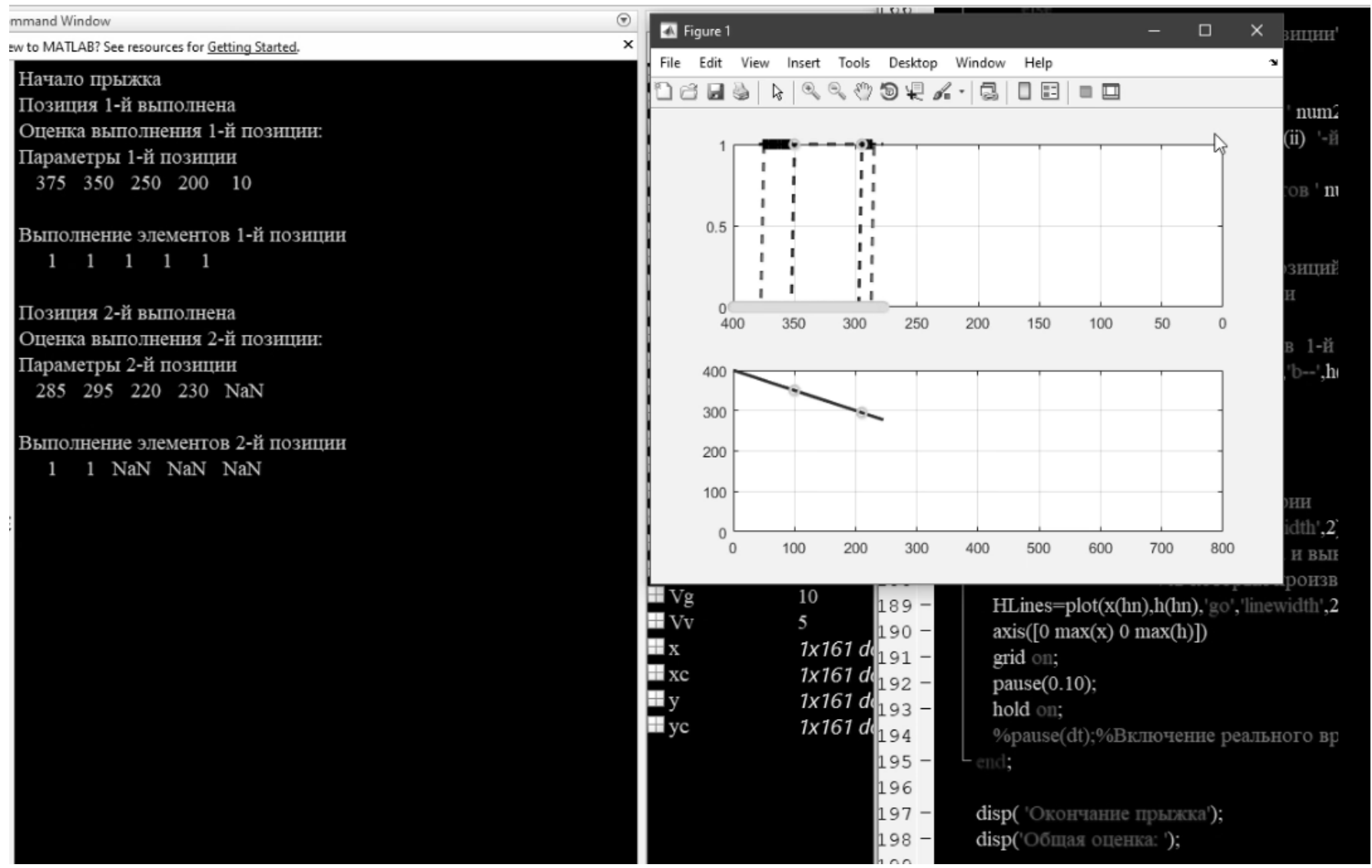

Рис. 4. Начало поэтапного контроля выполнения действий при прохождении парашютистом условно девяти контрольных позиций, в поле моделируемой траектории управляемого снижения парашютиста 


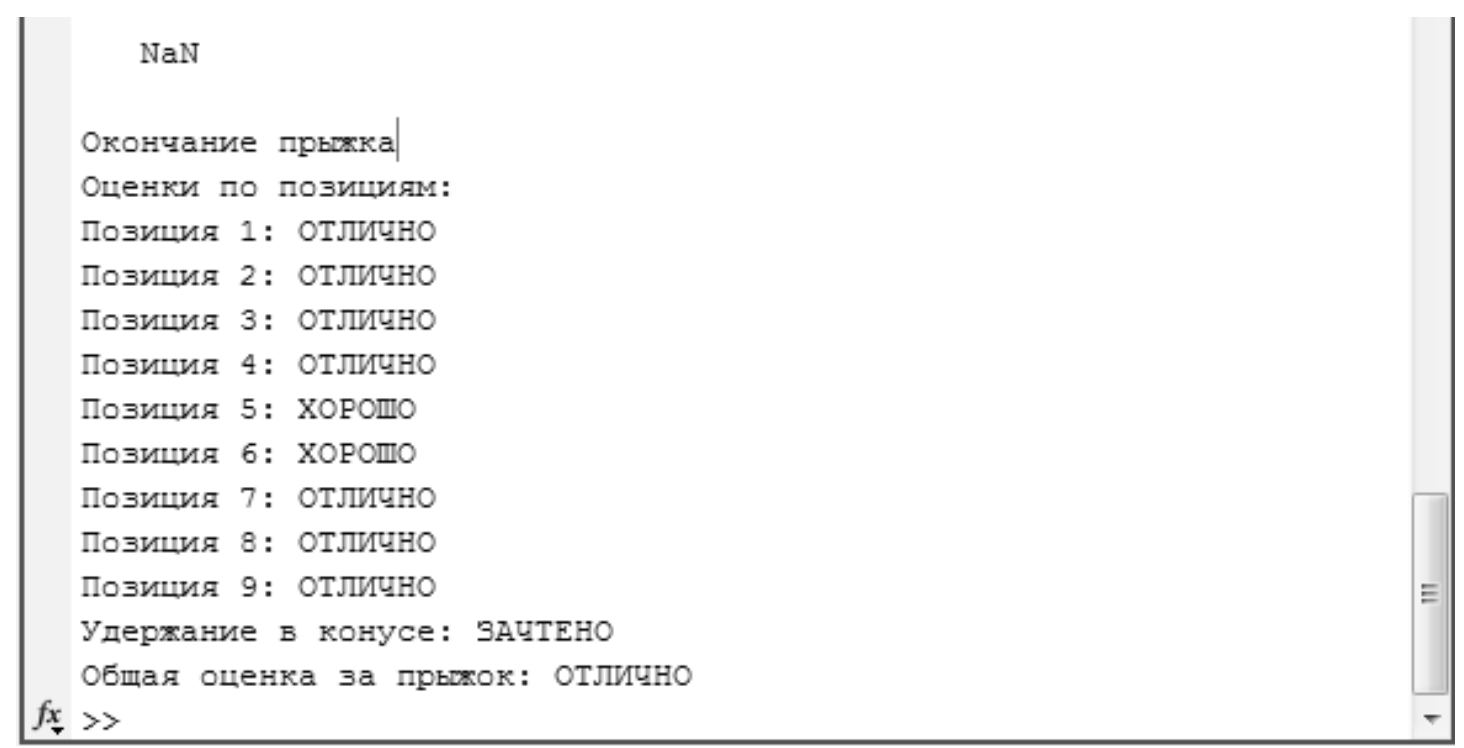

Рис. 5. Вывод результатов оценки в командную консоль

Информация о выполнении действий поступает с датчиков тренажёра. Для оценки данного типа параметров могут использоваться сложные комбинации датчиков (например, акселерометров) и (или) система машинного зрения.

С технической точки зрения автоматизированная оценка действий является более сложно реализуемым процессом, по сравнению с оценкой числовых параметров. Оценка действий в процессе выполнения контрольных позиций происходит по двухбалльной шкале: «0-не выполнено» или «1-выполнено», на рисунке 4 красной пунктирной линией показаны параметры выполненные парашютистом по первой позиции, синей пунктирной линией показано выставление оценки за позицию [9].

Это связано с тем, что с одной стороны алгоритмизировать оценку выполнения действий по шкале с большим числом баллов затруднительно. С другой - правильность действий в процессе выполнения позиции является критической с точки зрения выработки навыков пилотирования парашюта. Дифференциация оценки может способствовать закреплению неправильных навыков при работе на тренажёре, что недопустимо с точки зрения техники безопасности. При дальнейшей доработке алгоритма дифференциация возможна, но это потребует обоснования весовых коэффициентов, учитывающих важность или критичность выполнений того или иного действия в процессе выполнения контрольной позиции.

В разработанном алгоритме автоматизированной оценки действий парашютиста структура всех под- программ схожа. Они работают по сходному алгоритму, отличающемуся лишь в деталях. Такая унификация позволяет легко дорабатывать существующие подпрограммы и добавлять новые, делая алгоритм универсальным для проведения автоматического оценивания прыжков с парашютом на тренажёре, с учётом особенностей конкретных парашютных систем.

Подпрограммы построены следующим образом, на первом этапе выполнения подпрограммы фиксируется маркер начала выполнения позиции $A(j)$. Если этот маркер имеет логическое значение «0», то выполнение позиции еще не начиналось. В момент фиксации начала выполнения позиции на высоте $h(j)$ и ниже маркер $A(j)$ имеет логическое значение «1». Если выполнение позиции начато, то вначале происходит измерение числовых параметров позиции, на основе данных поступающих с датчиков или из вычислительного центра тренажёра, затем определяется выполнение элементов контрольной позиции (действий) в текущем проходе основного цикла. В случае реального тренажёра эта информация поступает с датчиков и фиксируется в логическом и числовом массивах данных соответственно, а при работе программы имитационного моделирования значения параметров задаются заранее, до начала её работы, либо формируются с помощью генератора случайных чисел.

После этого происходит считывание маркера окончания позиции $C(j)$. Данный маркер имеет логическое значение «0» до тех пор, пока не закончиться выполнение позиции. После завершения действий контрольной позиции на высоте $h(j)$ маркер $C(j)$ получает логическое значение «1». 
Если в процессе исполнения подпрограммы проверки выполнения $i$-й позиции маркер $C(j)$ становиться равным «1», то производиться выставление оценки за данную позицию. При этом сначала оценивается каждый числовой параметр, и выставляется низшая оценка из полученных:

$$
\text { Оценка }{ }_{i}=\min \left(R p_{1}, R p_{2}, \ldots R p_{n}\right) \text {, }
$$

где $R p_{1}, R p_{2}, \ldots R p_{n}$ - оценки $i$-й позиции по $n$-мy числовому параметру по четырёх бальной шкале.

Перед этим происходит оценка выполнения действий (логических параметров). Оценка в этом случае производится по формуле:

$$
\text { Оценка }_{\text {действий }}=\prod_{n=1}^{N} R p_{n} \text {. }
$$

Если оценка действий равна нулю, то вычисление оценки числовых параметров не производится и за позицию выставляется оценка «2-неудовлетворительно».

Выставление итоговой оценки происходит по следующему алгоритму:

1. Если за одну из позиций Оценка ${ }_{i}=2$, то итоговая оценка «2-неудовлетворительно»;

2. Если минимальная оценка за позицию не ниже «3-удовлетворительно», то итоговая оценка находится как среднее арифметическое оценок за все контрольные позиции, с округлением в сторону ближайшего целого;

3. В случае, если имел место выход из конуса возможностей, т.е. существует $R_{K}(j)=1$, то за прыжок выставляется неудовлетворительная оценка.

Пункт 3 алгоритма выставления итоговой оценки основан на том, что выход из «конуса возможностей» делает невозможным приземление парашютиста в заданную точку.

По окончанию работы автоматизированной оценки действий парашютиста производится формирование общего результата из оценок по каждой контрольной позиции, и выводится информация на рабочее место инструктора. Если алгоритм выполнялся на тренажёре то вывод результата возможен в командную консоль рисунок 5.

Обобщая представленный материал, сформированы выводы:

1. Представленный алгоритм обработки информации имеет логико-математическую структуру; разработан впервые и реализуется для автоматизации отдельных функций инструктора динамического тренажера освоения парашютных систем типа «крыло». Предложен путь реализации алгоритма в программе на языке MATLAB.

2. Обоснованы числовые и логические параметры подлежащих оцениванию с использованием средств автоматизации. Представлены особенности оценивания умений, обучающихся по показателю их нахождения в конусе возможностей в зависимости от факторов, влияющих на них. В качестве основного оценочного показателя предложено расстояние от оси «идеальной траектории полета» до условной материальной точки подвижной системы «Парашютист - ПС».

3. Из приведенного материала, очевидно, что предложенный алгоритм автоматизированной оценки действий парашютиста при пилотировании парашюта типа «крыло» позволяет минимизировать влияние человеческого фактора на определение качества подготовки и, как следствие, повысить эффективность управления уровнем освоения парашютной системой.

\section{ЛИТЕРАТУРА}

1. Алгоритмы действий десантника при совершении прыжка с парашютной системой специального назначения «Арбалет-1» В штатной и нештатной ситуации [Текст]: Свидетельство о гос. регистрации базы данных 2020622175 Рос. Федерация // Шлыков Ю.Н. [и др.]; Право0бладатель РВВДКУ (RU); заяв. 2020622074 29.10.2020; опубл. 06.11.2020, Бюл. № 11-2с.

2. Алгоритмы действий десантника при совершении прыжка с парашютной системой специального назначения «Арбалет-2» в штатной и нештатной ситуации [Текст]: Свидетельство о гос. регистрации базы данных 2020622136 Рос. Федерация // Шлыков Ю.Н. [и др.]; Правообладатель РBВДКУ (RU); заяв. 2020622070 29.10.2020; опубл. 03.11.2020, Бюл. № 11-2с.

3. Шлыков Ю.Н., Абанин В.С., Кутовой С.С. Подготовка парашютистов к освоению планирующих парашютных систем // Армейский сборник. 2019. № 8 (8). С. 51-57.

4. Просвирин В.Г., Абанин В.С., Кутовой С.С., Кругликов В.Я. Теоритическое обоснование алгоритмов управления подвижностью для динамического тренажера «Кудесник» // Научный резерв. 2019. № 2 (6). С. 38-43.

5. Абанин В.С. Оценка уровня адекватности учебных средств, применяемых при освоении планирующих парашютов, на основе анализа систем управления воздействиями на обучаемого // Современная наука: актуальные проблемы теории и практики. Серия: Естественные и Технические Науки. - 2020. -№ 03. -С. 70-76. 
6. Абанин В.С. Система автоматизированной оценки деятельности парашютиста для управления содержанием учебных сценариев в перспективном облике тренажера // Современная наука: актуальные проблемы теории и практики. Серия: Естественные и Технические Науки. - 2019. -№ 12. -С. 35-40

7. Абанин В.С., Кутовой С.С., Шлыков Ю.Н. Моделирование процесса наземной подготовки парашютистов для автоматизации управления учебными сценариями и реализации в перспективном облике тренажера // Современная наука: актуальные проблемы теории и практики. Серия: Естественные и Технические Науки. - 2019. -№ 11. -С. 32-38.

8. Бюшгенс А.Г., Кутовой С.С., Шлыков Ю.Н. Использование промышленного робота в качестве системы подвижности авиационного тренажера // Научный резерв. 2019. № 3 (7). С. 30-35.

9. Программа автоматизированной оценки действий парашютиста при освоении парашютной системой специального назначения на динамическом тренажере [Текст]: Свидетельство о гос. регистрации программы для ЭВМ 2020666973 Рос. Федерация // Шлыков Ю.Н. [и др.]; Правообладатель РВВДKУ (RU); заяв. 2020666527 04.12.2020; опубл. 18.12.2020, Бюл. № 12-1с.

○ Шлыков Юрий Николаевич ( shlykov76@mail.ru ), Абанин Владислав Сергеевич (vlad-ac@mail.ru ),

Кутовой Сергей Степанович ( kutovoyss@mail.ru ), Першин Андрей Сергеевич ( Sima-per@rambler.ru ).

Журнал «Современная наука: актуальные проблемы теории и практики»

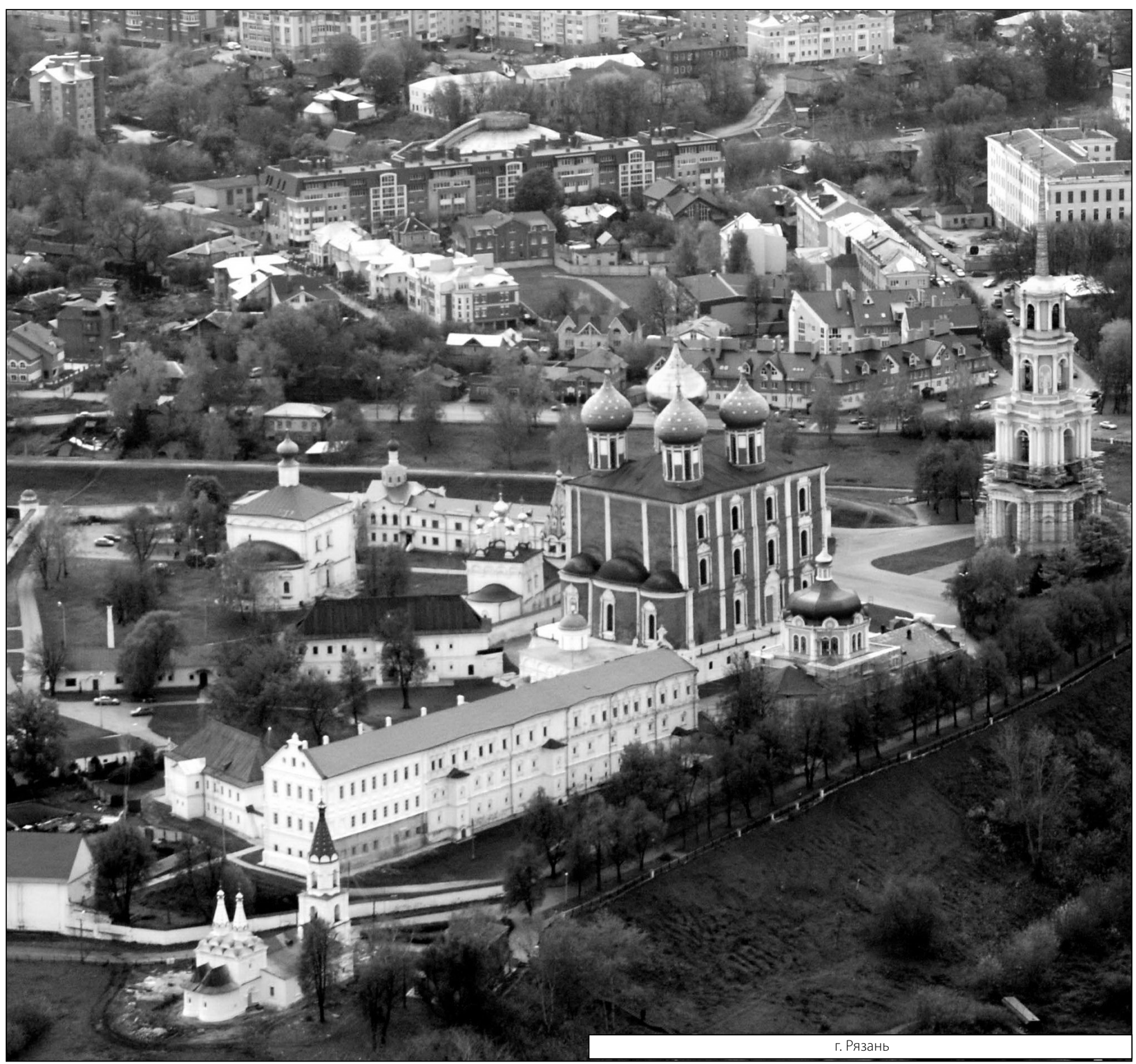

